\title{
Microcracks in granitoids of the Aldan shield and its effect on mechanical properties
}

\author{
Vladimir V. Efremov \\ Lomonosov Moscow State University, Faculty of Geology; GSP-1, Leninskie Gory, Moscow, 119991, Russia; \\ e-mail:vve1994@gmail.com
}

(C) 2015 Authors. This is an open access publication, which can be used, distributed and reproduced in any medium according to the Creative Commons CC-BY 4.0 License requiring that the original work has been properly cited.

Rock jointing is a ubiquitous feature of rocks. Joints are formed at the moment of rock creation and also later in response to e.g. tectonic stress or uplift. In engineering geology the intensity of jointing is a particular measure of rock quality, as it largely defines the mechanical properties of rocks i.e. in respect to its suitability as building ground.

Archean granites of the Elkon deposit, situated in the Aldan shield (South Yakutia, Russia), where chosen as the object of research. Microcracks of petrogenetic (formed due to magma cooling and crystallization) and tectonic origin have been observed in the rocks and the main goal was to analyze the effect of microcracks on rock strength and deformation.

Density, porosity, uniaxial compressive strength and elastic modulus of the rocks were determined according to standard approaches (Sergeev 1984). Elastic constants were determined with two methods: 1) calculated from the measured wave velocities and the bulk density (dynamic testing), and 2) unconfined compressive loading and stressstrain curve (static testing). Micro jointing has been explored by various research methods, such as: 1) macroscopic description of polished microsections, 2) examination of polished microsections with reflected light optical microscopy, 3) examination of polished microsections with fluorescent luminophore saturation. Acquired images of polished microsections were used to calculate the joint hollowness coefficient. It was calculated as a ratio between square of joints and total square of polished section. According to the joint hollowness coefficient rock samples were classified as moderately and intensely jointed.

It was observed, that the higher joining rate, the lower ultimate uniaxial compressive strength. This tendency is controlled by the presence of sliding surfaces which were formed due to tectonic movement and also microfractures in crystals.

The elastic modulus also decreases with an increase of the rock jointing rate. It should be noted, that dynamic elastic modulus is higher than the static by 2.5-3 times. The effect of rock jointing on the dynamic elastic modulus is explained by the abundance of open cracks - in the case of the open cracks shear-waves attenuate and primary waves slow down considerably. For the statistic elastic modulus, the loading of the sample leads to the closing of rock joint surfaces, thus increasing the inelastic (residual) strain component. Residual strain displayed inversely proportional dependence with uniaxial compressive strength.

\section{REFERENCES}

Sergeev E.M., 1984. Metodičeskoe posobie po inženerno-geologičeskomu izučeniû gornyh porod. V 2-h tomah. Nedra, Moskva. 